\title{
Time-Motion Characteristics AND Physiological Responses of Small-Sided Games in Elite Youth Players: The Influence of Player Number and Rule Changes
}

\author{
Stephen V. Hill-HaAs, ${ }^{1,2}$ Aaron J. Coutts, ${ }^{3}$ Brian T. Dawson, ${ }^{1}$ and Greg J. Rowsell ${ }^{2}$ \\ ${ }^{1}$ School of Sports Science, Exercise, and Health, University of Western Australia, Perth, Australia; ${ }^{2}$ Sport Science Unit, South \\ Australian Sports Institute, Adelaide, Australia; and ${ }^{3}$ School of Leisure, Sport, and Tourism, University of Technology Sydney, \\ Sydney, Australia
}

\begin{abstract}
Hill-Haas, SV, Coutts, AJ, Dawson, BT, and Rowsell, GJ. Timemotion characteristics and physiological responses of smallsided games in elite youth players: The influence of player number and rule changes. J Strength Cond Res 24(8): 21492156, 2010-The aim of this study was to examine acute physiological responses and time-motion characteristics associated with 4 soccer-specific small-sided game (SSG) formats ( 3 vs. 4 players, 3 vs. 3 players + floater, 5 vs. 6 players, and 5 vs. 5 players + floater) and 4 rule changes in elite youth soccer players. Sixteen male youth soccer players (mean $\pm S D$ : age $=15.6 \pm 0.8$ years, stature $=170.8 \pm 6.6 \mathrm{~cm}$, body mass $=67.5 \pm 6.2 \mathrm{~kg}$, and $20-\mathrm{m}$ shuttle run estimated $\dot{\mathrm{V}}_{2} \max =57.4 \pm 3.7 \mathrm{ml} \cdot \mathrm{kg}^{-1} \cdot \mathrm{min}^{-1}$ ) participated in the study, in which heart rate $(H R)$, rating of perceived exertion (RPE), blood lactate $\left(\mathrm{La}^{-}\right)$, and time-motion characteristics were recorded. The rule change requiring extra sprint running had a greater effect on the time-motion characteristics than all other rule modifications but no effect on acute \%HRmax, $\mathrm{La}^{-}$, and RPE. Rule changes had no effect on RPE. Fixed underload teams (i.e., lower number of players compared with the opponent team) recorded a significantly higher RPE compared with the fixed overload teams, although there were no differences in \%HRmax and $\mathrm{La}^{-}$. The major practical findings are that subtle changes in SSGs playing rules can influence the physiological, perceptual, and time-motion responses in young elite soccer players. Rules that are related to a team's chances of scoring may improve player motivation and thereby increase training intensity during SSGs. There were no differences between fixed and variable formats in terms of physiological
\end{abstract}

Address correspondence to: Stephen V. Hill-Haas, hillhaas.stephen@ gmail.com.

24(8)/2149-2156

Journal of Strength and Conditioning Research

(C) 2010 National Strength and Conditioning Association and perceptual responses, although both may provide useful technical-tactical training. Coaches should take care in designing different soccer SSGs as each rule or game format change may influence exercise intensity independently.

KEY WoRDS overload, game format, rule modifications, sprints

\section{INTRODUCTION}

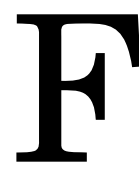

or optimal performance in team sports like soccer, players are required to maximize their technical, tactical, and physical abilities. Small-sided games (SSGs) training in soccer has been suggested as a training mode that may be able to concurrently improve these qualities (6). Indeed, it is widely believed that by altering pitch size, player number, or game rules independently, the physiological, perceptual, and physical loads can be manipulated to provide different training responses. However, the influence of altering these variables concurrently (e.g., player number and game rules) on the exercise intensity is not well understood. This is important because soccer coaches and conditioning staff commonly attempt to control the training intensity of soccer players by altering these variables. A better understanding of the influence of modifying these variables on SSG exercise intensity will assist coaches in controlling the training process for soccer players.

Recent studies have shown that SSG formats with different player numbers elicit different physiological, perceptual, and time-motion characteristics $(1,15)$. In general, these studies have shown that SSG formats with fewer players elicit greater heart rate (HR), blood lactate, and perceptual responses but less highspeed running than the larger formats $(9,12)$. However, these previous studies have only examined the influence of altering the player numbers on teams but maintaining a numerical balance between opposing teams (e.g., 2 vs. 2 players and 4 vs. 4 players). In practice, it is common for coaches to use SSG formats that involve playing a team with a fixed numerical advantage (overload) against a team with a fixed numerical disadvantage (underload) (e.g., 4 vs. 3 players and 6 vs. 5 
players). It is also common to use SSG formats that involve variable "overload" and "underload" situations, which are achieved using a "floater" player. This player transitions to the team in possession of the ball to create temporary overload and underload situations. The latter SSG design is typically used to develop defensive or attacking proficiency or increase the physical demands of the "floating" player. At present, the impact of creating fixed and temporary overload and underload situations on the physiological, perceptual, and time-motion responses in SSGs has not been investigated.

It is also common for coaches to modify the playing rules of SSGs to alter the physical and technical loads imposed on players. Examples of SSG rule modifications include restricting the number of touches on the ball a player or team may have or implementing an offside rule. These rule modifications have been designed in an attempt to replicate the technical (passing the ball and ball control) and tactical (being aware of the offside rule) demands of the game. Additionally, an "artificial" rule change such as requiring players to complete additional sprints at set time periods during each SSG is used to superimpose additional physical work on the players. Although some previous studies (2-4) have briefly described the effects of some technical rule changes on the exercise intensity of SSGs, these studies have used low samples or very short game durations. Therefore, at present, the effects of both technical and artificial rule changes on physiological, perceptual, and time-motion characteristics, in the context of both fixed and variable overload SSGs, are not well understood.

To our knowledge, there have been no studies that have examined the combined influence of fixed and variable player overload number or rule modifications on exercise intensity and time-motion demands of soccer SSGs. This information may be useful to coaches who are interested in using SSGs to develop the technical, tactical, and physical abilities in soccer players. Therefore, the aim of this study was to examine acute physiological responses and time-motion characteristics associated with 4 soccer-specific SSG formats (3 vs. 4 players, 3 vs. 3 players + floater, 5 vs. 6 players, and 5 vs. 5 players + floater) and 4 rule changes in elite youth soccer players. It was hypothesized that the artificial rule change, which required planned additional higher speed running, would have a significantly greater effect on time-motion characteristics than the other technical rule changes, with no differences in physiological or perceptual responses. The technical rule changes included an offside rule being in effect (rule change 1), all players must be in the front 2 zones of the pitch for a goal to count (rule change 2 ), and the use of 2 neutral players positioned outside but along the lengths of the pitch (rule change 3 ). The secondary hypothesis was that there would be no significant differences between fixed and variable overload SSG formats.

\section{Methods}

Experimental Approach to the Problem

Currently, the effects of both technical and artificial rule changes on physiological, perceptual, and time-motion characteristics, in the context of both fixed and variable overload SSGs, are not well understood. To test the hypothesis, both the player number and the rules were manipulated in an attempt to alter the intensity of the SSGs. Four different rule changes that are commonly used by soccer coaches were applied in 4 soccer-specific SSG formats (3 vs. 4 players, 3 vs. 3 players + floater, 5 vs. 6 players, and 5 vs. 5 players + floater $)$.

\section{Subjects}

Sixteen male youth soccer players (mean $\pm S D$ : age $=15.6 \pm$ 0.8 years, stature $=170.8 \pm 6.6 \mathrm{~cm}$, body mass $=67.5 \pm 6.2 \mathrm{~kg}$, and $20-\mathrm{m}$ shuttle run estimated $\dot{\mathrm{V}}_{2} \mathrm{max}=57.4 \pm 3.7$ $\mathrm{ml} \cdot \mathrm{kg}^{-1} \cdot \mathrm{min}^{-1}$ ) participated in the study. All subjects were members of a state team based at a sports institute in Australia. All players and parents were notified of the research procedures, requirements, benefits, and risks before giving informed consent. A university research ethics committee granted approval for the study.

\section{Procedures}

A 4-week preseason training period served as a familiarization for all the SSG formats and rule changes. The coach regularly applied the same game formats and rule changes as part of normal training. The coach used a subjective skill assessment of each player to allocate players into balanced SSG teams. The skill assessment was done by a very experienced coach, who had been coaching the same players for 2 years. The player's fitness score (20-m shuttle run) (10) was not used to allocate players into the various teams because the squad was at a similar fitness level (no outliers).

\section{Small-Sided Games}

The games were played once per week over the first 16 weeks of the competitive season period, with players selected on the same teams against the same opponents. The games were played at the beginning of each training session, following a standardized 20-minute warm-up. When the ball was kicked out of play, immediate access to a replacement soccer ball was made possible by having a supply of balls placed in the goals and along the boundary line surrounding the entire pitch. All the SSGs were played in random order over the 16-week duration of the study.

\section{Small-Sided Game Variables}

Table 1 shows a summary of the variables used in the study. In this study, the player number and rules were manipulated in an attempt to alter the intensity of the SSGs and were similar to those used in previous studies $(13,14,17)$. Smaller and larger SSG formats were used during the study. The smaller formats included 3 vs. 4 players and 3 vs. 3 players +1 floater, and the larger formats included 5 vs. 6 players and 5 vs. 5 players + floater. The pitch sizes (length $\times$ width) for the smaller and larger games were $37 \times 28$ and $47 \times 35 \mathrm{~m}$, respectively. 
TABLE 1. Small-sided game variables.

Small-sided game format

\begin{tabular}{|c|c|c|c|c|}
\hline Player number & 3 vs. 4 & 3 vs. 3 ( +1 floater) & 5 vs. 6 & 5 vs. 5 (+1 floater) \\
\hline \multicolumn{5}{|l|}{ Variables } \\
\hline Game duration (min) & 24 & 24 & 24 & 24 \\
\hline Grid total area $\left(\mathrm{m}^{2}\right)$ & 1,036 & 1,036 & 1,645 & 1,645 \\
\hline Pitch ratio per player $\left(\mathrm{m}^{2}\right)$ & $1: 148$ & $1: 148$ & $1: 149$ & $1: 149$ \\
\hline Grid size (length $\times$ width) $(\mathrm{m})$ & $37 \times 28$ & $37 \times 28$ & $47 \times 35$ & $47 \times 35$ \\
\hline Goalkeepers & No & No & Yes & Yes \\
\hline Coach encouragement & Yes & Yes & Yes & Yes \\
\hline Pitch layout & \multicolumn{4}{|c|}{ Pitch divided into 3 equal zones } \\
\hline Goals (height $\times$ width) & \multicolumn{2}{|c|}{ Minigoals used $(1.2 \times 1.8 \mathrm{~m})$} & \multicolumn{2}{|c|}{$\begin{array}{l}\text { Normal size goals used } \\
\quad(2.4 \times 7.3 \mathrm{~m})\end{array}$} \\
\hline \multicolumn{5}{|l|}{ Small-sided game rules } \\
\hline "Rule 1" & \multicolumn{4}{|c|}{ "Conditions a + b" } \\
\hline "Rule 2" & \multicolumn{4}{|c|}{ "Conditions $\mathrm{a}+\mathrm{b}+\mathrm{c}$ " } \\
\hline "Rule 3" & \multicolumn{4}{|c|}{ "Conditions $a+b+c+d "$} \\
\hline "Rule 4" & \multicolumn{4}{|c|}{ "Conditions $a+b+c+d+e "$} \\
\hline
\end{tabular}

"Condition a": offside rule in effect (front one-third zone of the pitch). "Condition b": kick in only (ball cannot be thrown in if it leaves the grid). "Condition c": all attacking team players must be in front 2 zones for a goal to count. "Condition d": alongside, but outside the lengths of each pitch, 2 neutral players can move up and down the pitch but not enter the grid. Before a shot on goal is permitted, the attacking team must pass the ball to either of these players. The ball can also be passed to either player in the defensive half. Each player is only allowed a maximum of 1 touch on the ball. "Condition e": 1 player from each team ("a pair") completes 4 repetitions of "sprint the widths/jog the lengths" on a 90-second interval ( 3 vs. 4 and 3 vs. $3+1$ floater games) or 3 repetitions on an 80 -second interval ( 5 vs. 6 and 5 vs. $5+1$ floater games). Total distance traveled per player, regardless of game format, would be approximately $440 \mathrm{~m}$.

\section{Rating of Perceived Exertion}

Global rating of perceived exertion (RPE) was recorded immediately after each SSG using the 6-20 scale (2). Standardized instructions for RPE were given (3), but subjects were asked to refer their RPE to the exercise bout just completed rather than their perceived exertion at the time of rating. Exercise anchoring for the RPE scale was completed during familiarization with the various SSG formats during preseason training. The reliability of RPE has been previously reported (8), with the typical error expressed as a percentage of the mean (TE\%) being 1-2 units.

\section{Blood Sampling}

Capillary blood samples were drawn from an earlobe within 5 minutes following each SSG and immediately analyzed using a Lactate Pro (LT-1710; Arkray, Kyoto, Japan) analyzer. Blood samples were taken from each player in every game, and they were drawn from the same players in the same order following each game. The analyzer was regularly calibrated using precision standards and routinely assessed by external quality controls. The reliability of blood lactate has been previously reported (8), with $\mathrm{TE} \%$ ranging between 16 and $34 \%$.

\section{Heart Rate Monitoring}

Heart rate was recorded at 5-second intervals during each SSG via short-range radiotelemetry (Polar Team Sport
System; Polar Electro Oy, Kempele, Finland). The HR monitors were also worn during periodic $20-\mathrm{m}$ shuttle run assessments to determine each player's maximum HR (HRmax). Exercise intensity during each SSG was assessed using HR, expressed as percent HRmax and classified into 4 previously defined intensity zones: zone 1 ( $<75 \%$ HRmax), zone 2 (75-84\% HRmax), zone 3 (85-89\% HRmax), and zone 4 (>90\% HRmax) (7). The HRmax reached during the $20-\mathrm{m}$ shuttle run assessment was used as a reference value for each of the 4 intensity zones (7). Both the actual and the percentage time in each zone for each player during all SSGs were recorded. The reliability of HRmax has been previously reported (8), with TE\% being less than 5\%.

\section{Time-Motion Characteristics}

Player movements during the SSGs were measured using portable global positioning system (GPS) units (SPI 10; GPSports, Canberra, Australia). The SPI 10 was placed into a harness that positioned the device between the player's shoulder blades, which was worn by every player during all SSGs. The distance traveled was recorded at $1 \mathrm{~Hz}$. For data analysis purposes, 3 speed zones were selected: speed zone 1 (standing and walking, 0-6.9 $\mathrm{km} \cdot \mathrm{h}^{-1}$ ), speed zone 2 (jogging and cruising, 7.0-13.0 $\mathrm{km} \cdot \mathrm{h}^{-1}$ ), and speed zone 3 (higher intensity running, $>13.0 \mathrm{~km} \cdot \mathrm{h}^{-1}$ ). The reliability of the SPI-10 GPS device for measuring team sport-specific movement characteristics following a known running course has 
TABLE 2. Physiological and time-motion responses to small-sided games according to rule changes (mean $\pm S D$ ).

\begin{tabular}{|c|c|c|c|c|c|c|c|c|c|}
\hline Factor & $N$ & Rule & Condition & $\begin{array}{c}\text { Total } \\
\text { distance }(\mathrm{m})\end{array}$ & $\begin{array}{c}\text { Mean speed } \\
\left(\mathrm{m} \cdot \mathrm{min}^{-1}\right)\end{array}$ & $\begin{array}{c}\text { Higher } \\
\text { Intensity } \\
\text { Running } \\
>13.0 \mathrm{~km} \cdot \mathrm{h}^{-1}(\mathrm{~m})\end{array}$ & RPE (6-20) & $\begin{array}{c}\text { Heart rate } \\
\text { (\% maximum })\end{array}$ & $\begin{array}{c}\text { Blood lactate } \\
\text { concentration } \\
\left(\mathrm{mmol} \cdot \mathrm{L}^{-1}\right)\end{array}$ \\
\hline $\begin{array}{l}\text { All games } \\
\text { Bonferroni } \\
\text { post hoc } \\
\text { test }\end{array}$ & $\begin{array}{l}48 \\
47 \\
46 \\
50\end{array}$ & $\begin{array}{l}1 \\
2 \\
3 \\
4\end{array}$ & $\begin{array}{c}a+b \\
a+b+c \\
a+b+c+d \\
a+b+c+d+e\end{array}$ & $\begin{array}{c}2,464 \pm 267 \\
2,502 \pm 200 \\
2,523 \pm 212 \\
2,672 \pm 197 \\
\text { Rule } 4 \S>\text { Rule } 3\end{array}$ & $\begin{array}{c}103 \pm 11 \\
104 \pm 8 \\
105 \pm 9 \\
111 \pm 8 \\
\text { Rule } 4 \S>\text { Rule 3 }\end{array}$ & $\begin{array}{c}537 \pm 200 \\
519 \pm 157 \\
484 \pm 146 \\
748 \pm 134 \\
\text { Rule } 4^{\|}>\text {Rule } 3\end{array}$ & $\begin{array}{c}15.7 \pm 1.5 \\
15.5 \pm 1.9 \\
14.8 \pm 1.1 \\
15.0 \pm 1.4 \\
\text { Rule } 1^{\|}>\text {Rule 3; } \\
\text { Rule } 2^{\|}>\text {Rule 3 }\end{array}$ & $\begin{array}{c}82.0 \pm 3.9 \\
84.0 \pm 4.4 \\
81.2 \pm 4.7 \\
82.5 \pm 4.1 \\
; \text { Rule } 2 \|^{\|}>\text {Rule } 3\end{array}$ & $\begin{array}{l}2.6 \pm 1.0 \\
2.8 \pm 1.0 \\
2.3 \pm 1.1 \\
2.6 \pm 1.0 \\
\quad \text { NSD }\end{array}$ \\
\hline $\begin{array}{l}3 \text { vs. } 4 \text { and } 3 \\
\text { vs. } 3+1 \\
\text { floater } \\
\text { games } \\
\text { Bonferroni } \\
\text { post hoc } \\
\text { test }\end{array}$ & $\begin{array}{l}24 \\
23 \\
23 \\
26\end{array}$ & $\begin{array}{l}1 \\
2 \\
3 \\
4\end{array}$ & $\begin{array}{c}a+b \\
a+b+c \\
a+b+c+d \\
a+b+c+d+e\end{array}$ & $\begin{array}{c}2,439 \pm 166 \\
2,405 \pm 201 \\
2,450 \pm 223 \\
2,677 \pm 192 \\
\text { Rule } 4^{\|}>\text {Rule } 3\end{array}$ & $\begin{array}{l}102 \pm 7 \\
100 \pm 8 \\
102 \pm 9 \\
112 \pm 8\end{array}$ & $\begin{array}{r}451 \pm 200 \\
430 \pm 130 \\
452 \pm 145 \\
758 \pm 144 \\
\text { Rule } 4^{\|}>\text {Rule } 3\end{array}$ & $\begin{array}{l}15.8 \pm 1.6 \\
15.6 \pm 2.3 \\
14.8 \pm 1.2 \\
15.1 \pm 1.6 \\
\text { NSD }\end{array}$ & $\begin{array}{c}83.3 \pm 3.8 \\
84.8 \pm 3.8 \\
80.3 \pm 4.8 \\
83.7 \pm 4.0 \\
\text { Rule } 4 \|>\text { Rule } 3\end{array}$ & $\begin{array}{l}2.8 \pm 1.0 \\
2.4 \pm 0.8 \\
2.3 \pm 1.1 \\
2.8 \pm 1.1 \\
\text { NSD }\end{array}$ \\
\hline $\begin{array}{l}5 \text { vs. } 6 \text { and } 5 \\
\text { vs. } 5+1 \\
\text { floater } \\
\text { games } \\
\text { Bonferroni } \\
\text { post hoc } \\
\text { test }\end{array}$ & $\begin{array}{l}21 \\
22 \\
20 \\
21\end{array}$ & $\begin{array}{l}1 \\
2 \\
3 \\
4\end{array}$ & $\begin{array}{c}a+b \\
a+b+c \\
a+b+c+d \\
a+b+c+d+e\end{array}$ & $\begin{array}{c}2,471 \pm 355 \\
2,583 \pm 147 \\
2,614 \pm 178 \\
2,639 \pm 189 \\
\text { NSD }\end{array}$ & $\begin{array}{c}103 \pm 15 \\
108 \pm 6 \\
109 \pm 7 \\
110 \pm 8 \\
\text { NSD }\end{array}$ & $\begin{array}{c}625 \pm 205 \\
595 \pm 127 \\
515 \pm 148 \\
731 \pm 111 \\
\text { Rule } 4 \S>\text { Rule } 3\end{array}$ & $\begin{array}{c}15.3 \pm 1.1 \\
14.9 \pm 1.4 \\
14.6 \pm 0.9 \\
14.9 \pm 1.1 \\
\text { NSD }\end{array}$ & $\begin{array}{l}81 \pm 4 \\
83 \pm 5 \\
83 \pm 5 \\
80 \pm 3 \\
\text { NSD }\end{array}$ & $\begin{array}{c}2.2 \pm 1.0 \\
3.2 \pm 1.2 \\
2.3 \pm 1.1 \\
2.4 \pm 0.9 \\
\text { Rule } 2 \S>\text { Rule 1; } \\
\text { Rule } 2 \S>\text { Rule } 3\end{array}$ \\
\hline $\begin{array}{r}\mathrm{NSD}=\mathrm{no} s \\
\text { "Condition a } \\
\text { must be in front } \\
\text { a shot on goal is } \\
\text { a maximum of } 1 \\
3+1 \text { floater gan } \\
440 \mathrm{~m} . \\
\quad \$ p<0.01 . \\
\| p<0.001 .\end{array}$ & & 年 & $\begin{array}{l}\text { differences; RPE }=\text { ra } \\
\text { ule in effect (front one } \\
\text { r a goal to count. "Co } \\
\text { the attacking team n } \\
\text { re ball. "Condition e": } \\
\text { petitions on an 80-se }\end{array}$ & $\begin{array}{l}\text { ting of perceived exert } \\
\text { third zone of the pitch). } \\
\text { dition d": outside, but } \\
\text { ust pass the ball to eith } \\
1 \text { player from each team } \\
\text { ond interval (5 vs. } 6 \text { an }\end{array}$ & $\begin{array}{l}\text { "Condition b": kick in } \\
\text { along the } 2 \text { lengths of } \\
\text { her of these players. Th } \\
n \text { ("a pair") completes } \\
\text { d } 5 \text { vs. } 5+1 \text { floater gan }\end{array}$ & $\begin{array}{l}\text { only (ball cannot be throv } \\
\text { each pitch, } 2 \text { neutral play } \\
\text { ee ball can also be passe } \\
4 \text { repetitions of "sprint the } \\
\text { mes). Total distance trave }\end{array}$ & $\begin{array}{l}\text { wn in if it leaves the pitc } \\
\text { yers can move up and } \\
\text { ed to either player in th } \\
\text { e widths/jog the length } \\
\text { eled per player, regardl }\end{array}$ & $\begin{array}{l}\text { ch). "Condition c": all } \\
\text { down the pitch but no } \\
\text { e defensive half. Each } \\
\text { hs" on a } 90 \text {-second in } \\
\text { less of game format, } \mathrm{W}\end{array}$ & $\begin{array}{l}\text { attacking team players } \\
\text { t enter the grid. Before } \\
\text { h player is only allowed } \\
\text { terval ( } 3 \text { vs. } 4 \text { and } 3 \text { vs. } \\
\text { vould be approximately }\end{array}$ \\
\hline
\end{tabular}


TABLE 3. Physiological and time-motion responses to small-sided games according to game format excluding the floater (mean $\pm S D$ ).

\begin{tabular}{|c|c|c|c|c|c|c|c|c|}
\hline Factor & Levels & $N$ & $\begin{array}{c}\text { Total } \\
\text { distance }(\mathrm{m})\end{array}$ & $\begin{array}{l}\text { Mean speed } \\
\left(\mathrm{m} \cdot \mathrm{min}^{-1}\right)\end{array}$ & $\begin{array}{c}\text { Higher } \\
\text { Intensity } \\
\text { Running } \\
>13.0 \mathrm{~km} \cdot \mathrm{h}^{-1}(\mathrm{~m})\end{array}$ & $\begin{array}{l}\text { RPE } \\
(6-20)\end{array}$ & $\begin{array}{l}\text { Heart rate } \\
(\% \\
\text { maximum })\end{array}$ & $\begin{array}{c}\text { Blood } \\
\text { lactate } \\
\text { concentration } \\
\left(\mathrm{mmol} \cdot \mathrm{L}^{-1}\right)\end{array}$ \\
\hline \multicolumn{9}{|l|}{ Player number } \\
\hline Matched & $\begin{array}{l}3 \text { vs. } 3 \text { and } 5 \text { vs. } \\
5 \text { teams } \\
\text { (excluding floater) }\end{array}$ & 83 & $2,585 \pm 204$ & $108 \pm 9$ & $582 \pm 190$ & $15.2 \pm 1.4$ & $82.5 \pm 4.6$ & $2.6 \pm 1.1$ \\
\hline Overload & $\begin{array}{l}\text { 6-player and } \\
\text { 4-player teams }\end{array}$ & 56 & $2,458 \pm 243$ & $102 \pm 10$ & $528 \pm 184$ & $14.7 \pm 1.5$ & $82.3 \pm 4.5$ & $2.6 \pm 1.0$ \\
\hline Underload & $\begin{array}{l}\text { 5-player and } \\
\text { 3-player teams }\end{array}$ & 41 & $2,535 \pm 247$ & $106 \pm 10$ & $598 \pm 192$ & $15.8 \pm 1.5$ & $82.3 \pm 4.0$ & $2.6 \pm 1.0$ \\
\hline $\begin{array}{l}\text { Bonferroni post } \\
\text { hoc test }\end{array}$ & & \multicolumn{3}{|c|}{ Matched $\ddagger>$ Overload Matched $\ddagger>$ Overload } & NSD & Underload $\neq>$ Overload & NSD & NSD \\
\hline
\end{tabular}

$\mathrm{NSD}=$ no significant differences; RPE $=$ rating of perceived exertion.

$\ddagger p<0.01$.

TABLE 4. Physiological and time-motion responses to small-sided games according to player number (mean $\pm S D$ ).

\begin{tabular}{|c|c|c|c|c|c|c|c|c|c|}
\hline Factor & Levels & $N$ & $\begin{array}{c}\text { Total } \\
\text { distance }(\mathrm{m})\end{array}$ & $\begin{array}{c}\text { Mean speed } \\
\left(\mathrm{m} \cdot \mathrm{min}^{-1}\right)\end{array}$ & $\begin{array}{l}\text { Higher Intensity } \\
\text { Running } \\
>13.0 \mathrm{~km} \cdot \mathrm{h}^{-1}(\mathrm{~m})\end{array}$ & $\begin{array}{l}\text { Sprint number } \\
\left(>18.0 \mathrm{~km} \cdot \mathrm{h}^{-1}\right)\end{array}$ & RPE (6-20) & $\begin{array}{c}\text { Heart rate } \\
(\% \text { maximum })\end{array}$ & $\begin{array}{c}\text { Blood lactate } \\
\text { concentration } \\
\left(\mathrm{mmol} \cdot \mathrm{L}^{-1}\right)\end{array}$ \\
\hline \multicolumn{10}{|l|}{ Player number } \\
\hline & 3 players & 12 & $2,543 \pm 187$ & $106 \pm 8$ & $553 \pm 187$ & $10 \pm 6$ & $16.3 \pm 1.6$ & $82.3 \pm 3.5$ & $2.5 \pm 0.7$ \\
\hline & 4 players & 16 & $2,408 \pm 231$ & $100 \pm 10$ & $482 \pm 178$ & $8 \pm 4$ & $14.6 \pm 1.9$ & $83.1 \pm 4.0$ & $2.5 \pm 0.9$ \\
\hline \multirow{5}{*}{ Scheffe post hoc } & Floater & 8 & $2,668 \pm 220$ & $111 \pm 10$ & $628 \pm 132$ & $9 \pm 6$ & $16.3 \pm 1.5$ & $82.7 \pm 3.0$ & $2.3 \pm 0.8$ \\
\hline & & & Floater $\div>4$ & Floater $\neq>4$ & NSD & NSD & Floater§ $>4$ & NSD & NSD \\
\hline & 5 players & 20 & $2,526 \pm 302$ & $105 \pm 13$ & $649 \pm 190$ & $9 \pm 5$ & $15.2 \pm 1.0$ & $82.5 \pm 5.0$ & $2.5 \pm 1.0$ \\
\hline & 6 players & 24 & $2,524 \pm 247$ & $105 \pm 10$ & $589 \pm 177$ & $8 \pm 4$ & $14.9 \pm 0.9$ & $81.4 \pm 5.1$ & $2.6 \pm 1.1$ \\
\hline & Floater & 4 & $2,610 \pm 201$ & $109 \pm 8$ & $673 \pm 194$ & $15 \pm 3$ & $16.3 \pm 1.7$ & $82.5 \pm 5.6$ & $2.8 \pm 0.2$ \\
\hline Scheffe post hoc & & & NSD & NSD & NSD & $\begin{array}{l}\text { Floater§ > 5; } \\
\quad \text { floater§ }>6\end{array}$ & NSD & NSD & NSD \\
\hline
\end{tabular}

$\mathrm{NSD}=$ no significant differences; RPE $=$ rating of perceived exertion

$\ddagger p<0.01$.

$\ddagger p<0.01$.
$\S p<0.001$. 
previously been reported, with the typical error expressed as a coefficient of variation being $3.6 \%$ for total distance, $4.3 \%$ for low-intensity activity $\left(0-6.9 \mathrm{~km} \cdot \mathrm{h}^{-1}\right), 11.2 \%$ for higher intensity running $\left(>14.4 \mathrm{~km} \cdot \mathrm{h}^{-1}\right)$, and $5.8 \%$ for peak speed (5).

\section{Statistical Analyses}

The data are reported as mean $\pm S D$. Before using parametric tests, the assumption of normality was verified using the Shapiro-Wilk $W$ test. To determine the effects of rule changes, game format, and player number, a main effects 2-way analysis of variance with a Bonferroni post hoc was used. All statistical analyses were performed using the software package STATISTICA (7.0 version; Statsoft, Tulsa, OK), and significance was set at $p \leq 0.05$.

\section{Results}

\section{Rule Changes (Main Effects)}

Table 2 shows the physiological, perceptual, and timemotion characteristics according to rule changes. With all game formats combined, "sprint the widths/jog the lengths" of the pitch (rule change 4) compared with all the other rule changes (refer Table 2) elicited significantly greater total distance traveled and higher intensity running. The RPE associated with the offside rule in effect (rule change 1) and all players having to be in the front 2 zones of the pitch for a goal to count (rule change 2) were significantly higher compared with using 2 neutral players positioned outside but along the lengths of the pitch (rule change 3). For \%HRmax, "rule change 2," requiring all players to be in the front 2 zones, was also significantly higher compared with all other rule changes. There were no significant differences for blood $\left[\mathrm{La}^{-}\right]$between any of the rules (Table 2$)$.

For smaller game formats ( 3 vs. 4 players and 3 vs. 3 players + floater), total distance traveled and higher intensity running for "sprint the widths/jog the lengths" of the pitch (rule change 4) were significantly greater compared with all other rule changes. There was no significant difference between any rule changes for RPE or blood $\left[\mathrm{La}^{-}\right]$. However, \%HRmax was significantly lower for games using 2 neutral players positioned outside, along the lengths of the pitch (rule change 3 ) compared with "rule change 1" (i.e., the offside rule in effect), "rule change 2" (i.e., all players must be in front 2 zones), and "rule change 4" (i.e., "sprint the widths/jog the lengths" of the pitch) (Table 2).

For larger game formats ( 5 vs. 6 players and 5 vs. 5 players + floater), significantly greater higher intensity running was completed by adding a rule that required players to "sprint the widths/jog the lengths" of the pitch (rule change 4) compared with all other rule changes. There were no significant differences between any of the rule changes for RPE and $\%$ HRmax. However, blood $\left[\mathrm{La}^{-}\right]$was significantly higher for games requiring all players to be in the front 2 zones of the pitch for a goal to count (rule change 2) compared with the offside rule in effect (rule change 1) and games using 2 neutral players positioned outside, along the lengths of the pitch (rule change 3 ).

\section{Game Format (Main Effects)}

Table 3 shows the physiological, perceptual, and timemotion characteristics according to game format. The data from the "floaters" were excluded from the main effects analysis to reduce any potential confounding effects the floater player may have on player number. The total distance traveled between "matched" teams ( 3 vs. 3 players and 5 vs. 5 players) was significantly higher compared with overload teams (6-player and 4-player teams) $(p<0.007 ; 2,585 \pm 204$ and 2,458 $\pm 243 \mathrm{~m}$, respectively). The RPE associated with underload teams (5-player and 3-player teams) was significantly higher compared with overload teams (6-player and 4-player teams) $(p<0.005 ; 16 \pm 1$ and $15 \pm 2$, respectively). There were no significant differences in higher intensity running (distance traveled at $>13 \mathrm{~km} \cdot \mathrm{h}^{-1}$ ), \%HRmax, and blood $\left[\mathrm{La}^{-}\right]$between any of the game formats (Table 3 ).

\section{Player Number (Main Effects)}

Table 4 shows the physiological, perceptual, and timemotion characteristics associated with player number, including the floater. For the smaller game formats, the floater traveled a significantly greater total distance compared with 4-player teams $\left(p<0.01 ; 2,668 \pm 220 \mathrm{~m}\right.$ or $111 \pm 9 \mathrm{~m} \cdot \mathrm{min}^{-1}$ vs. $2,408 \pm 231 \mathrm{~m}$ or $100 \pm 10 \mathrm{~m} \cdot \mathrm{min}^{-1}$, respectively). The RPE associated with 3-player teams was significantly higher compared with that associated with 4-player teams $(p<$ $0.003 ; 16 \pm 2$ and $15 \pm 2$, respectively). There were no significant differences between player numbers (3 players and 4 players) in higher intensity running (distance traveled at $>13 \mathrm{~km} \cdot \mathrm{h}^{-1}$ ), sprint number, $\% \mathrm{HRmax}$, and blood $\left[\mathrm{La}^{-}\right]$ (Table 4).

For the larger game formats, the floater completed a significantly greater amount of sprints $\left(>18.0 \mathrm{~km} \cdot \mathrm{h}^{-1}\right)$ compared with 5-player and 6-player teams $(p<0.002 ; 15 \pm$ 3 vs. $9 \pm 5$ and $8 \pm 4$, respectively). There were no significant differences between player numbers (including the floater) in total distance traveled, higher intensity running (distance traveled at $>13 \mathrm{~km} \cdot \mathrm{h}^{-1}$ ), RPE, \%HRmax, and blood $\left[\mathrm{La}^{-}\right]$ (Table 4).

\section{Discussion}

The primary aim of this study was to examine the acute physiological and perceptual responses and time-motion characteristics associated with 4 SSG formats (3 vs. 4 players, 3 vs. 3 players +1 floater, 5 vs. 6 players, and 5 vs. 5 players + 1 floater) with 4 different playing rules. The main finding was that the different playing rules modify the time-motion, physiological, and perceptual responses in aerobically fit elite youth soccer players. Furthermore, changes in game formats and variations in player number appear to have a greater influence on time-motion characteristics and perceptual responses than on the physiological responses. 
The artificial rule change that required the players to sprint the widths and jog the lengths of the pitch (rule change 4) had a greater effect on the time-motion characteristics (total distance traveled, higher intensity running, and number of sprints) than all other rule modifications. However, despite imposing a greater external training load on each game, the artificial rule change had no effect on the blood lactate and perceptual responses. This is in agreement with the primary hypothesis of this study. One possible reason for this may be a "pacing effect" because of the relatively long duration (24 minutes) of these games. Players may have responded by reducing the tempo of play, and thereby the physiological and perceptual load, as a strategy to endure each game (4).

In contrast, a technical rule change that required all players from the attacking team to be in the front two-thirds of the pitch for a score (goal) to count (rule change 2) significantly increased $\% \mathrm{HRmax}$ and blood $\left[\mathrm{La}^{-}\right]$in both small and large game formats, respectively. Despite the duration of the game, this rule change may not have induced a significant pacing strategy because scoring a goal would not have elicited large increases in total distance covered. These results suggest that technical rules that are related to a team's chance of scoring a goal may influence the player's motivation to increase or maintain exercise intensity and therefore enhance the player's physiological response to SSGs.

Both the technical and the artificial rule changes used in this study had no effect on RPE. This finding is in contrast to previous studies that reported an increase in blood $\left[\mathrm{La}^{-}\right]$ (player-to-player marking) (1), RPE (maximum of 2 touches on the ball) (16), and \%HRmax (pressure half switch) (11) with specific rule changes during SSGs. It is possible that the technical load of the SSGs in this study did not provide sufficient strain, and therefore, the RPEs of the high-level youth soccer players in this study did not increase. This aspect of SSG design in soccer requires further investigation.

At various times during a soccer match, players will encounter situations where the number of players around the ball from each team may be "matched," "underloaded" (i.e., outnumbered), or "overloaded" in relation to their opponents. This study showed that temporarily matched teams (3 vs. 3 players and 5 vs. 5 players) during the variable overload games worked harder than fixed overload formats (6-player and 4player teams). The presence of a floater may have provided a greater incentive for each team to work harder to gain possession and thereby gain the benefit of having a floater join their team. Indeed, although the practical value of variable format (overload-underload) games used in this study did not differ physiologically or perceptually from the fixed formats (in agreement with the secondary hypothesis of this study), their real value may be to increase the technical load on each player (e.g., the number of ball contacts per player). The technical load of both variable and fixed formats requires further investigation.

Despite fixed underload teams (5-player and 3-player teams) recording a significantly higher RPE compared with the fixed overload teams (6-player and 4-player teams), there were no differences in time-motion characteristics and physiological responses. Although there are no similar studies that have examined the demands of fixed underload soccer SSGs, a recent study examined the effect of an early dismissal on player work-rate in a professional soccer match (4). The early dismissal (after 5 minutes of a 90-minute match) resulted in an increase in total distance traveled and less recovery time between high-intensity efforts by the numerically disadvantaged team (4). The time-motion data from the present study did not show similar findings with the numerically disadvantaged teams as there were no significant differences in the time-motion characteristics. Again, it is possible that the SSG duration ( 24 minutes) may not have been long enough to induce changes in time-motion responses as reported over the 90 -minute match. It is also possible that the numerically disadvantaged teams in this study adopted defensive patterns (such as zone defense) and other tactical adjustments to reduce fatigue associated with a fixed numerical disadvantage. Technical analysis of these games may have provided evidence to support this, and therefore, further research is required.

Variations in player number have generally been found to affect SSG training intensity. In this study, time-motion characteristics (total distance traveled) and acute perceptual responses were affected but not physiological responses. The RPE of the 3-player teams was higher compared with that of 4-player teams. This finding is similar to other studies $(1,16)$ that reported an increase in RPE with a reduction in player number when pitch size remained constant.

In contrast, variations in player number in larger formats (5-player and 6-player teams) did not have any effect on acute physiological, perceptual, or time-motion characteristics. Possible reasons include the large pitch size negating the effects of variations in player number and the floater constituting relatively less proportion of total player number.

Floaters were included in this SSGs study to determine the effects of this role on time-motion characteristics and acute physiological and perceptual responses. The floater results should be interpreted with caution, given the low sample size. In this study, floaters traveled greater total distance in the small format (3-4 sided) games and completed more sprints in the large format (5-6 sided) games. In the presence of a floater, frequent changes in ball possession between opposing teams may require the floater to travel greater distances at submaximal speeds, thereby increasing total distance. Additionally, with more absolute pitch space available in larger format games, the floater would have more space available for higher speed running efforts. Despite the higher submaximal work-rate of the floater compared with other players in both small and large game formats, this did not translate to significantly greater perceptual or physiological responses. One possible reason is the floater is usually not required to tackle. The reduced physical contact 
may have lowered the acute perceptual and physiological responses.

\section{Practical Applications}

The major findings of this study are that subtle changes in SSG playing rules can influence the physiological, perceptual, and time-motion responses in young elite soccer players. For example, the rule change that requires players to complete preprogrammed extra sprint efforts around the pitch during each game (rule change 4) can be used to impose a greater external training load on elite youth soccer players. In contrast, changes in technical rules (e.g., rule change 2) that are related to a team's chances of scoring may improve player motivation and thereby increase the exercise intensity during SSGs.

There were no significant differences between fixed and variable formats in terms of physiological and perceptual responses. Despite this, both formats may provide a useful variation in SSGs training or as a technical-tactical training method for defensive and attacking plays. The possibility of variable formats proving a greater technical load needs to be substantiated by further research. Finally, the use of a floater appears to be more effective in smaller format games and may be appropriate for either maintaining or developing aerobic fitness.

Collectively, the results of this study provide new information about the effectiveness of using SSGs as a training stimulus for soccer. This new information relating to variables affecting SSGs intensity may be useful for prescribing soccerspecific aerobic conditioning programs for elite youth soccer players. However, caution should be applied to interpretation of the time-motion results because the sampling rate of the GPS units was $1 \mathrm{~Hz}$. This reduces the reliability of velocity data $>20 \mathrm{~km} \cdot \mathrm{h}^{-1}(5)$. We suggest that coaches should take care in designing different soccer SSGs as each rule or game format change may influence exercise intensity independently. Therefore, to increase the effectiveness of these changes from a conditioning perspective, it may be better to manipulate technical rule changes and SSG player numbers separately.

\section{ACKNOWLeDGMents}

In memory of Martyn Crook, the former head coach of the Australian National U17 and South Australian Sports Institute men's soccer squads. We thank him for his coaching expertise and commitment to this project. To all the players, thank-you for your time and effort during the SSGs. We would also like to thank Polar Electro Oy (Finland) for sponsoring the Polar Team Sport System HR monitors and software. The results of the present study do not constitute endorsement of the product by the authors or the journal.

\section{REFERENCES}

1. Aroso, J, Rebelo, AN, and Gomes-Pereira, J. Physiological impact of selected game-related exercises. J Sports Sci 22: 522, 2004.

2. Borg, G. Perceived exertion as an indicator of somatic stress. Scand J Rehabil Med 2: 92-98, 1970.

3. Borg, G. Borg's Perceived Exertion and Pain Scales. Champaign: Human Kinetics, 1998.

4. Carling, $\mathrm{C}$ and Bloomfield, J. The effect of an early dismissal on player work-rate in a professional soccer match. J Sci Med Sport 2008. doi:10.1016/j.jsams.2008.09.004.

5. Coutts, AJ and Duffield, R. Validity and reliability of GPS units for measuring movement demands of team sports. J Sci Med Sports 2008. doi:10.1016/j.jsams.2008.09.015.

6. Gabbett, TJ and Mulvey, MJ. Time-motion analysis of small-sided training games and competition in elite women soccer players. $J$ Strength Cond Res 22: 543-552, 2008.

7. Gore, C, ed. Physiological Tests for Elite Athletes. Champaign: Human Kinetics, 2000.

8. Hill-Haas, S, Coutts, A, Rowsell, G, and Dawson, B. Variability of acute physiological responses and performance profiles of youth soccer players in small-sided games. J Sci Med Sport 11: 487-490, 2008.

9. Hill-Haas, S, Dawson, B, Coutts, A, and Rowsell, G. Physiological responses and time-motion characteristics of various small-sided soccer games in youth players. J Sports Sci 2008. doi:10.1080/ 02640410802206857.

10. Leger, L and Lambert, J. A maximal multistage 20-m shuttle run test to predict $\dot{\mathrm{V}}_{2}$ max. Eur J Appl Physiol 49: 1-2, 1982.

11. Little, T and Williams, AG. Suitability of soccer training drills for endurance training. J Strength Cond Res 20: 316-319, 2006.

12. Little, T and Williams, AG. Measures of exercise intensity during soccer training drills with professional soccer players. J Strength Cond Res 21: 367-371, 2007.

13. Owen, A, Twist, C, and Ford, P. Small-sided games: The physiological and technical effect of altering pitch size and player numbers. Insight 7: 50-53, 2004

14. Rampinini, E, Coutts, AJ, Castagna, C, Sassi, R, and Impellizzeri, FM. Variation in top level soccer match performance. Int J Sport Med 28: 1-7, 2007.

15. Rampinini, E, Impellizzeri, FM, Castagna, C, Abt, G, Chamari, K, Sassi, A, and Marcora, SM. Factors influencing physiological responses to small-sided soccer games. J Sports Sci 25: 659-666, 2007.

16. Sampaio, J, Garcia, G, Macas, V, Ibanez, J, Abrantes, C, and Caixinha, P. Heart rate and perceptual responses to $2 \times 2$ and $3 \times 3$ small-sided youth soccer games. J Sports Sci Med 6(Suppl 10): 1-222, 2007.

17. Williams, $\mathrm{K}$ and Owen, A. The impact of player numbers on the physiological responses to small sided games. J Sports Sci Med 6(Suppl 10): 100, 2007. 